\begin{tabular}{|c|c|c|}
\hline $\mathrm{Cas}$ & \multicolumn{2}{|c|}{ Case Rep Gastroenterol 2015;9:165-170 } \\
\hline Ogy & $\begin{array}{l}\text { DOI: 10.1159/000382071 } \\
\text { Publisnea onine: IVlay Z2, } 2015\end{array}$ & $\begin{array}{l}\text { (C) } 2015 \text { S. Karger AG, Basel } \\
1662-0631 / 15 / 0092-0165 \$ 39.50 / 0 \\
\text { www.karger.com/crg }\end{array}$ \\
\hline & \multicolumn{2}{|c|}{$\begin{array}{l}\text { This is an Open Access article licensed under the terms of the Creative Commons } \\
\text { Attribution-NonCommercial } 3.0 \text { Unported license (CC BY-NC) (www.karger.com/OA } \\
\text { license), applicable to the online version of the article only. Distribution permitted for non } \\
\text { commercial purposes only. }\end{array}$} \\
\hline
\end{tabular}

\title{
Prone Position Is Useful in Thoracoscopic Enucleation of Esophageal Leiomyoma
}

\author{
Kenji Maki ${ }^{a}$ Shinsuke Takeno ${ }^{a}$ Satoshi Nimurab ${ }^{b}$ Ippei Yamana ${ }^{a}$ \\ Hideki Shimaoka $^{a}$ Tatsuya Hashimoto ${ }^{a}$ Ryousuke Shibata ${ }^{a}$ \\ Hironari Shiwaku $^{a}$ Kanefumi Yamashita ${ }^{a}$ Yuichi Yamashita ${ }^{a}$ \\ Departments of a Gastroenterological Surgery and ${ }^{b}$ Pathology, Fukuoka University Faculty \\ of Medicine, Fukuoka, Japan
}

\section{Key Words}

Esophageal leiomyoma · Thoracoscopic enucleation · Prone position

\begin{abstract}
A 36-year-old man was admitted to our institute due to the diagnosis of esophageal submucosal tumor detected by a periodical upper gastrointestinal endoscopic examination without any complaint. Thoracoscopic enucleation of the lesion with the preoperative clinical diagnosis of esophageal leiomyoma was performed under general anesthesia in the prone position. After immunohistochemical examination, the pathological diagnosis was leiomyoma. There was no remarkable event during the postoperative hospital stay, and the patient was discharged on the 12th day after surgery. This case report suggests that the prone position might be superior to the left lateral decubitus position in thoracoscopic enucleation of esophageal leiomyoma.

(C) 2015 S. Karger AG, Basel
\end{abstract}

\section{Introduction}

Leiomyoma of the esophagus is one of the most common types of benign esophageal submucosal tumors [1]. To date, there have been several reports on its surgical treatment, and there seems to be a consensus that enucleation is a sufficient surgical treatment of esophageal leiomyoma. While enucleation has formerly been performed with open thoracotomy [2], recently, thoracoscopic enucleation of esophageal leiomyoma has been performed to achieve a minimally invasive surgery in parallel to the popular method of thoraco-

KARGER 125:s $\quad \begin{aligned} & \text { Kenji Maki } \\ & \text { Department of Gastroenterological Surgery } \\ & \text { Fukuoka University Faculty of Medicine } \\ & \text { Nanakuma 7-45-1, Johnan-ku, Fukuoka City, Fukuoka 814-0180 (Japan) } \\ & \text { E-Mail vkenjimaki@yahoo.co.jp }\end{aligned}$


Maki et al.: Prone Position Is Useful in Thoracoscopic Enucleation of Esophageal Leiomyoma

scopic surgery. However, most studies report that the surgery was performed in the left decubitus position [3-5].

In contrast, the prone position approach has been developed for esophagectomy in patients with esophageal cancer as initially reported by Cuschieri [6]. The prone position was given priority over the left decubitus position due to the mobilization of the esophagus; therefore, the authors performed enucleation of the esophageal leiomyoma in the prone position in the present case.

In this report, the authors present their experience with enucleation of esophageal leiomyoma by the thoracoscopic approach in the prone position, discuss the utility of the prone position, and offer a review of the literature.

\section{Case Report}

The patient was a 36-year-old healthy man without any past history. An esophageal submucosal tumor was discovered during a periodical medical examination. Endoscopic examination revealed the presence of an esophageal submucosal tumor ( $4 \mathrm{~cm}$ in diameter) in the middle thoracic esophagus (fig. 1). A computed tomography scan demonstrated a $4.5 \times 3.5 \mathrm{~cm}$-sized tumor in the middle thoracic esophagus (fig. 2). Leiomyoma of the esophagus was suspected in the preoperative examination.

Thoracoscopic enucleation in the prone position was planned. Surgery was performed under general anesthesia with a single-lumen endotracheal intubation and a bronchial blocker. A 6-mm Hg artificial pneumothorax using carbon dioxide was induced with left onelung ventilation.

Five trocars were used, three of $12 \mathrm{~mm}$ and two of $5 \mathrm{~mm}$. One of the 12-mm ports was placed at the 7 th intercostal space (ICS) at the middle axillary line for the $30^{\circ}$ endoscope. The other $12-\mathrm{mm}$ ports were placed at the 7th and 9th ICS at the posterior axillary line. The 5-mm ports were placed at the 3rd ICS at the middle axillary line and at the 5th ICS at the posterior axillary line (fig. 3).

The muscularis propria of the esophagus was cut using an electrosurgical knife to expose the capsule of the tumor, and a well-defined solid tumor with an intact capsule was enucleated (fig. 4). The divided muscularis propria was closed by interrupted sutures under a thoracoscopic approach.

Postoperatively, a nasogastric tube was kept in place for 2 days. Contrast radiography of the esophagus on the 4th postoperative day showed intact smooth esophageal mucosa with no leakage. The patient started peroral intake on the 4th postoperative day, and the chest drain tube was removed on the 6th postoperative day. There was no remarkable event after surgery, and the patient was discharged from hospital on the 12th day after surgery.

The final pathological diagnosis was leiomyoma of the esophagus without any malignant feature (fig. 5).

\section{Discussion}

Most esophageal submucosal tumors are leiomyoma, and its prevalence rate is reported to be approximately $70 \%$ [1]. To date, a consensus has been reached that enucleation of the tumor is a sufficient surgical treatment, and there is a trend towards the adoption of a thoracoscopic approach [2-5]. The superiority of the thoracoscopic approach compared to thoracotomy is that it is associated with less postoperative pain, atelectasis, and pleural effusion, 
Maki et al.: Prone Position Is Useful in Thoracoscopic Enucleation of Esophageal Leiomyoma

and its minimal surgical invasion seems to be suitable for surgery of benign esophageal submucosal tumors $[7,8]$.

Concerning the patient's position during the thoracoscopic enucleation, the left decubitus position with left one-lung ventilation has been selected for anesthesia in the thoracoscopic approach to date. In contrast, Cuschieri [6] initially reported on thoracoscopic esophagectomy in the prone position for esophageal cancer in 1994. Recently, this procedure has been adopted in the majority of minimally invasive surgeries for esophageal cancer because it is easy to mobilize the esophagus in this position. In addition, Palanivelu et al. [9] reported a low incidence of respiratory complications, a shortened operative time, and a low incidence of postoperative pneumonia because complete right-lung collapse in order to keep a good surgical view is not necessary due to gravity.

There have been previous reports on thoracoscopic enucleation of esophageal leiomyoma in the prone position [10-12]. Additionally, we report the present case. The results of the previous reports are summarized in table 1 . Every institution adopted left one-lung anesthesia with 6- to 8-mm Hg insufflated pressure. Blood loss was low. Concerning the hospital stay period, our case stayed for a prolonged period at the hospital compared to the patients in the other reports, but this depended on the Japanese health insurance system. Thus, the authors believe that thoracoscopic enucleation of esophageal leiomyoma in the prone position is a safe and feasible surgical procedure.

In conclusion, minimally invasive surgery should be performed for esophageal leiomyoma, and the prone position is safe and useful for thoracoscopic enucleation.

\section{References}

1 Hatch GF III, Wertheimer-Hatch L, Hatch KF, Davis GB, Blanchard DK, Foster RS Jr, Skandalakis JE: Tumor of the esophagus. World J Surg 2000;24:401-411.

2 Bardini R, Segalin A, Ruol A, Pavanello M, Peracchia A: Videothoracoscopic enucleation of esophageal leiomyoma. Ann Thorac Surg 1992;54:576-577.

$\$ 3$ Akaraviputh T, Chinswangwatanakul V, Swangsri J, Lohsiriwat V: Thoracoscopic enucleation of a large esophageal leiomyoma using a three thoracic ports technique. World J Surg Oncol 2006;4:70.

-4 Vallbohmer D, Holscher A, Brabender J, Bollschweiler E, Gutschow C: Thoracoscopic enucleation of esophageal leiomyomas: a feasible and safe procedure. Endoscopy 2007;39:1097-1099.

-5 Kent M, Amato T, Nordoman C, Schuchert M, Landreneau R, Alvelo-Rivera M, Luketich J: Minimally invasive resection of benign esophageal tumors. J Thorac Cardiovasc Surg 2007;134:176-181.

6 Cuschieri A: Thoracoscopic subtotal oesophagectomy. Endosc Surg Allied Technol 1994;2:21-25.

7 Von Rahden BH, Stein HJ, Feussner H, Siewert JR: Enucleation of submucosal tumors of the esophagus: minimally invasive versus open approach. Surg Endosc 2004;18:924-930.

-8 Priego P, Lobo E, Rodriguez G, Cabanas J, Perez de Oteyza J, Fresneda V: Endoscopic treatment of oesophageal leiomyoma: four new cases. Clin Transl Oncol 2007;9:106-109.

-9 Palanivelu C, Prakash A, Senthikumar R, Senthilnathan P, Parthasarathi R, Rajan PS, Venkatachlam S: Minimally invasive esophagectomy: thoracoscopic mobilization of the esophagus and mediastinal lymphadenectomy in prone position - experience of 130 patients. J Am Coll Surg 2006;203:7-16.

10 Palanivelu C, Rangarajan M, Senthikumar R, Annapoorni S, Jategaonkar PA: Thoracoscopic management of benign tumors of the mid-esophagus: a retrospective study. Int J Surg 2007;5:328-331.

11 Dapri G, Himpens J, Ntounda R, Alard S, Dereeper E, Cadiere GB: Enucleation of a leiomyoma of the midesophagus through a right thoracoscopy with the patient in prone position. Surg Endosc 2010;24:215-218.

12 Claus CM, Cury Fiho AM, Boscardim PC, Andriguetto PC, Loureiro MP, Bonin EA: Thoracoscopic enucleation of esophageal leiomyoma in prone position and single lumen endotracheal intubation. Surg Endosc 2013;27:3364-3369. 


\section{Case Reports in \\ Gastroenterology}

\begin{tabular}{l|l}
\hline \multicolumn{2}{l}{ Case Rep Gastroenterol 2015;9:165-170 } \\
\hline DOI: 10.1159/000382071 & $\begin{array}{l}\text { @ 2015 S. Karger AG, Basel } \\
\text { www.karger.com/crg }\end{array}$ \\
\hline
\end{tabular}

Maki et al.: Prone Position Is Useful in Thoracoscopic Enucleation of Esophageal Leiomyoma

Table 1. Previous reports on thoracoscopic enucleation of esophageal leiomyoma in the prone position

\begin{tabular}{lllll}
\hline First author [ref.] & $\begin{array}{l}\text { Operation time, } \\
\text { min }\end{array}$ & Blood loss & $\begin{array}{l}\text { Insufflated } \\
\text { pressure, mm Hg }\end{array}$ & $\begin{array}{l}\text { Hospital } \\
\text { stay, days }\end{array}$ \\
\hline Palanivelu [10] & $85-128$ & low & $6-8$ & $1-3$ \\
Dapri [1] & 85 & $20 \mathrm{ml}$ & - & 3 \\
Claus [12] & $45-135$ & low & 6 & 3.20 \\
\hline
\end{tabular}

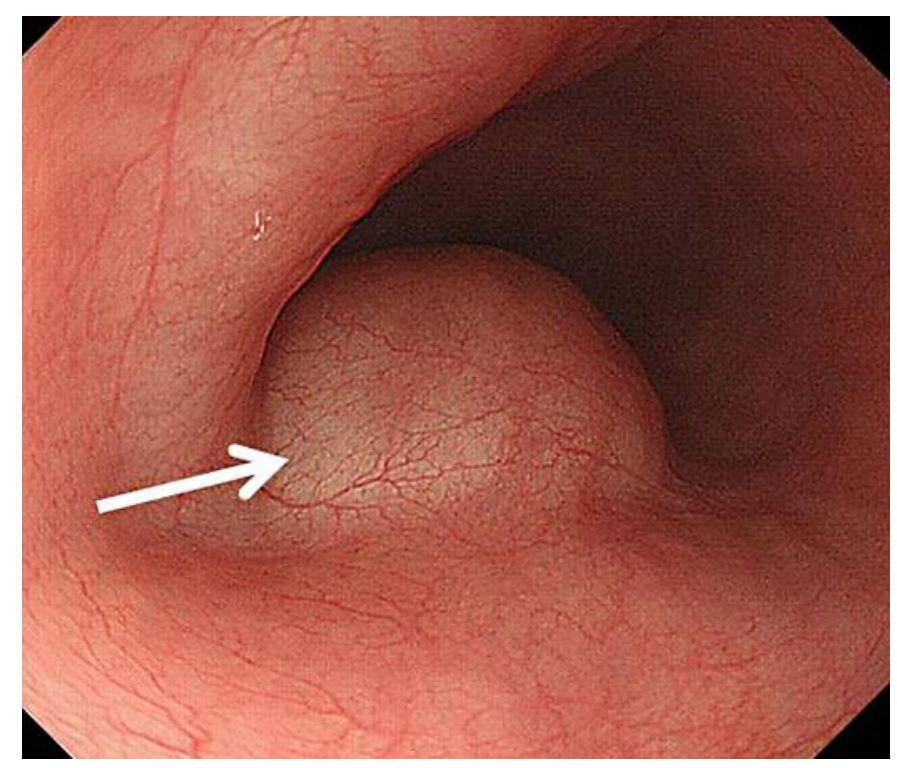

Fig. 1. Endoscopy revealed a protuberant lesion which was covered with normal esophageal mucosa (arrow) and suggested the presence of an esophageal submucosal tumor ( $4 \mathrm{~cm}$ in diameter) in the middle thoracic esophagus.

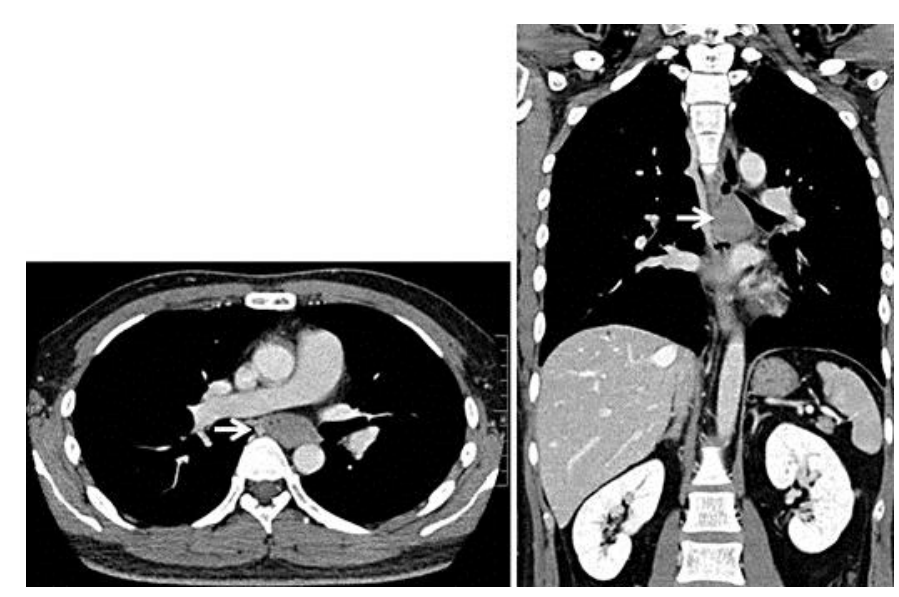

Fig. 2. Computed tomography scans demonstrated a $4.5 \times 3.5 \mathrm{~cm}$-sized tumor (arrow) in the middle thoracic esophagus. 


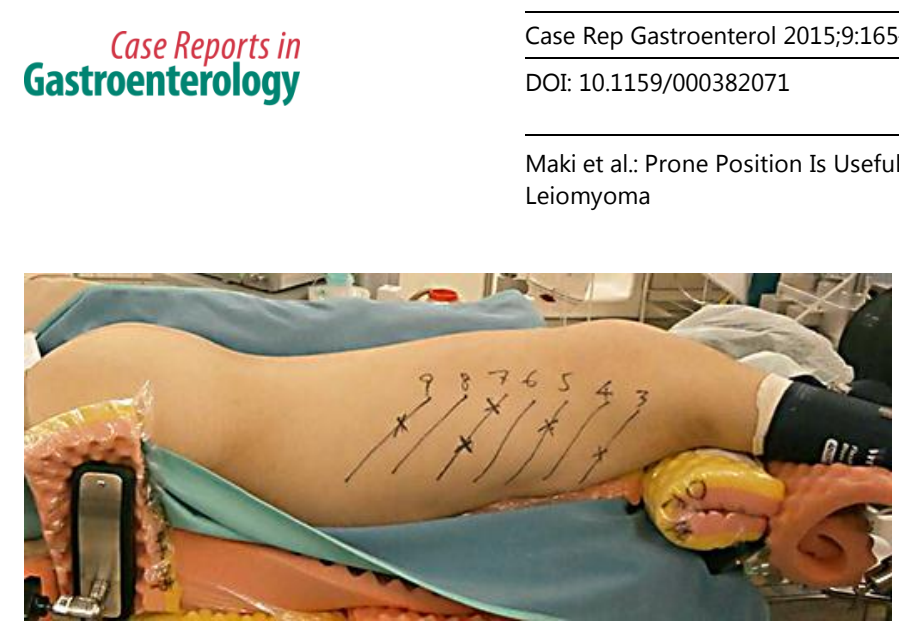

Fig. 3. The prone position for thoracoscopic enucleation was demonstrated in the present case.

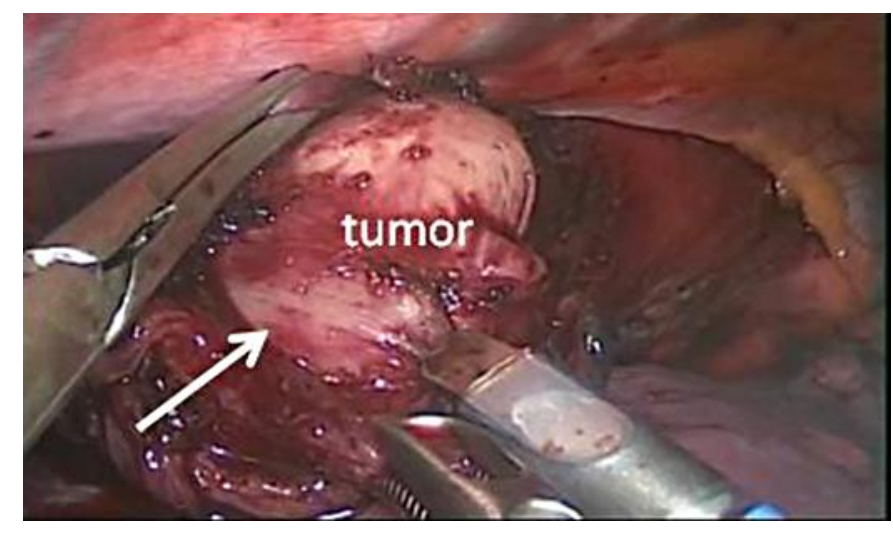

Fig. 4. The submucosal tumor (arrow) was enucleated with a thoracoscopic approach. 
Maki et al.: Prone Position Is Useful in Thoracoscopic Enucleation of Esophageal Leiomyoma
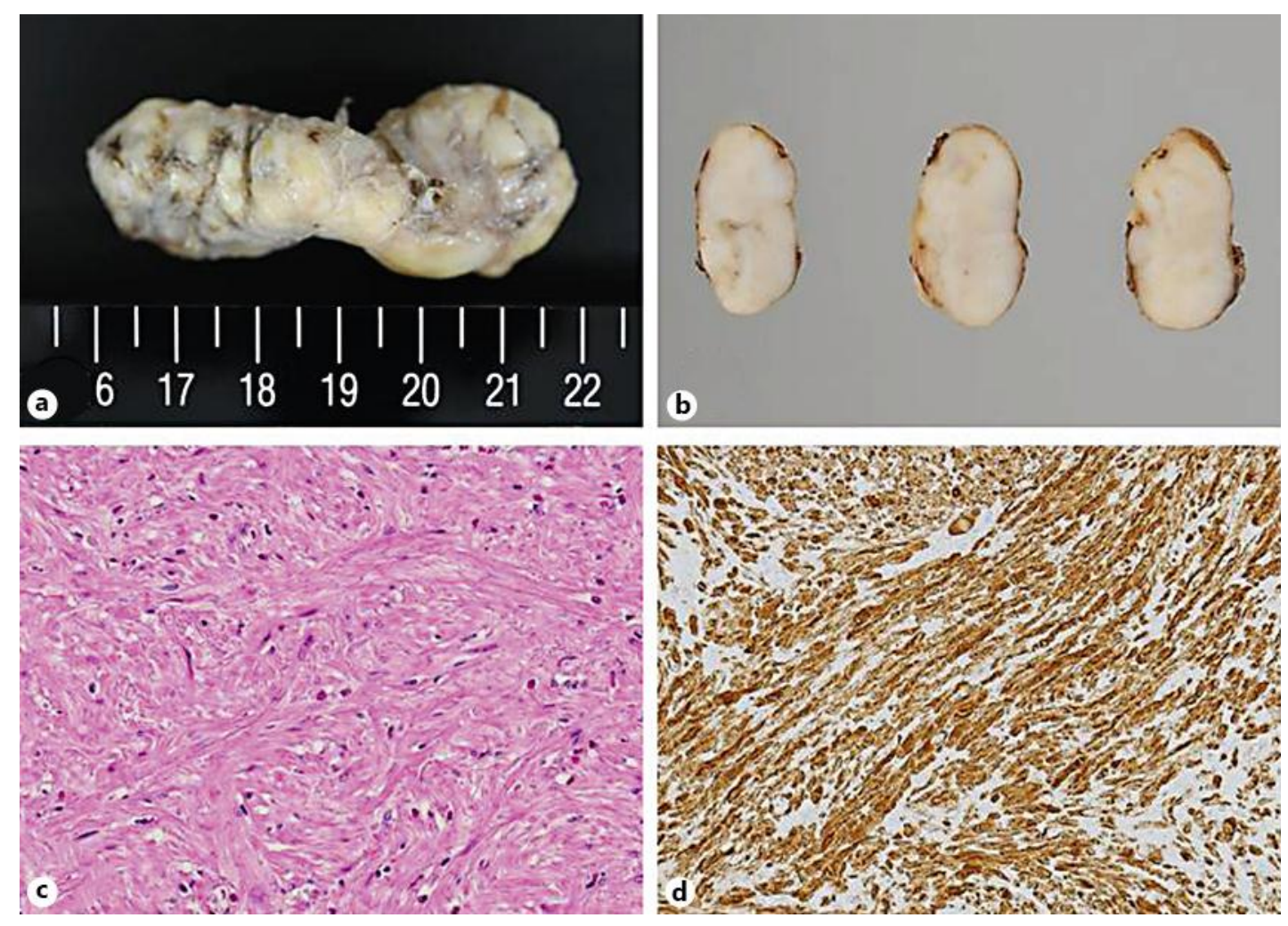

Fig. 5. Pathological features of the tumor. a Grossly, the tumor had an elongated dimension, presenting as a sausage-shaped mass. $\mathbf{b}$ The cut surfaces were of a grayish tan. c Microscopically, the tumor was composed of well-differentiated smooth muscle cells. Neither mitotic figures nor necrotic foci were detected in the tumor. HE. $\times 200$. d Immunohistochemically, the tumor cells were positive for desmin. They were almost negative for KIT. 